\title{
Effects of niacin supplementation on the insulin resistance in Holstein cows during early lactation
}

\author{
Talija Hristovska ${ }^{1}$, Marko R. Cincović ${ }^{2}$, Branislava Belić ${ }^{2}$, Dragica Stojanović ${ }^{2}$, \\ Milanka Jezdimirović ${ }^{3}$, Radojica Đoković ${ }^{4}$, Bojan Toholj ${ }^{2}$ \\ ${ }^{1}$ St. Clement of Ohrid University of Bitola, Veterinary Faculty, Bitola, Macedonia \\ ${ }^{2}$ University of Novi Sad, Faculty of Agriculture, Department of Veterinary Medicine, Novi Sad, Serbia \\ ${ }^{3}$ University of Belgrade, Faculty of Veterinary Medicine, Belgrade, Serbia \\ ${ }^{4}$ University of Kragujevac, Faculty of Agronomy, Kragujevac, Serbia
}

\author{
Received February 23, 2017
}

Accepted October 2, 2017

\begin{abstract}
Insulin resistance in early lactation includes low glucose concentration, low insulin release and responsiveness and high lipolysis. Niacin is important antilipolytic agent and leads to increase glucose and insulin concentration. The objectives of this study were to determine the influence of niacin on the insulin resistance in cows during early lactation using the difference of value and regression analysis between blood non-esterified fatty acid (NEFA), glucose and insulin concentrations, revised quantitative insulin sensitivity check index and glucose-to-insulin ratio. Niacin supplementation led to a decrease of NEFA concentration and an increase of glucose and insulin concentrations during the first three weeks after calving. Cows in the niacin group which were more resistant to insulin showed higher concentrations of non-esterified fatty acid in comparison with more sensitive cows from the same group, but still lower than the control. The regression analyses suggest the following characteristics of cows supplemented with niacin in comparison with the control group: the insulin response to glucose was more intense; the antilipolytic effect of insulin was lower; insulin efficiency expressed as glucose-to-insulin ratio increase with a decrease in NEFA. The metabolic changes due to niacin supplementation showed a dual influence on the insulin resistance in dairy cows during early lactation: decreased NEFA concentrations led to a decrease in the insulin resistance (due to an increase in insulin efficiency and insulin sensitivity index), but increased concentrations of insulin and glucose possibly caused an increase in the insulin resistance in dairy cows (due to lower insulin sensitivity index and possibly lower antilipolytic effects of insulin).
\end{abstract}

Cattle, nicotinic acid, transition period, glucose metabolism

The transitional period, from 3 weeks before to 3 weeks after parturition, is critically important to health, production, and profitability of dairy cows (Butler 2000). Dairy cows undergo tremendous changes during the transition from late gestation to early lactation (Drackley 1999). During early lactation, dairy cows undergo a state of negative energy balance (NEB) and they have to mobilize adipose stores to support energy requirements and milk fat synthesis. Large amounts of fat are mobilized and delivered to the liver via the circulation as non-esterified fatty acids (NEFAs). The concentration of NEFAs in the blood reflects the degree of adipose tissue mobilization (Pullen et al. 1989). Furthermore, NEFAs are used as alternate fuels for much of the rest of the body, and are also converted by the liver to ketones bodies (Drackley 1999), but in excess amounts they may be toxic (Bell 1995; Overton 2001). Elevated plasma NEFA concentrations are correlated with postpartum disorders (Dyk et al. 1995), depressed feed intake and increased triglyceride accumulation in the liver (Grummer 1993). Another important change during this period is the development of insulin resistance in peripheral tissues. Insulin resistance is defined as a condition when higher than normal insulin concentrations are needed to

Address for correspondence:

Marko R. Cincović

Department of Veterinary Medicine

Faculty of Agriculture

Phone: +381214853516

University of Novi Sad, Serbia 
achieve normal metabolic responses (Kahn 1978). Increased plasma NEFA concentrations have been associated with insulin resistance in mammals as fatty acids can cause insulin resistance in skeletal muscles by indirectly interfering with the insulin-stimulated glucose transport activity (Petersen and Schulman 2006). Pires et al. (2007) showed that the induction of hyperlipidaemia causes insulin resistance in Holstein cows by impairing both the sensitivity and maximum responsiveness to insulin. Moreover, they suggest that elevated NEFA concentrations during the periparturient period may potentially interrupt adipose tissue functions and that NEFAs may be a key factor triggering insulin resistance in Holstein cows.

As a precursor of the coenzyme nicotinamide adenine dinucleotide (NAD) and with the ability to maintain a large number of oxidation-reduction reactions (Bender 2003), niacin exerts antilipolytic effects and, in large doses, reduces the release of NEFAs from adipose tissue (Pires et al. 2007b; Morey et al. 2011). Antilipolytic effects of niacin are mediated by the activation of G protein-coupled GPR109A receptors, which exist in a functional form in cattle (Kenèz et al. 2014). Consequently, the inhibition of adenyl cyclase activity occurs, reducing the intracellular levels of cyclic adenosine monophosphate (cAMP) and resulting in the suppression of lipolysis (Wise et al. 2003).

We hypothesize that niacin administration to dairy cows in the transition period can influence the insulin responsiveness and resistance in adipose tissue by virtue of niacin-induced changes in NEFA, glucose and insulin concentrations.

\section{Materials and Methods}

Animals, treatments and blood collection

A total of 30 clinically healthy, multiparous Holstein-Friesian cows in late gestation were included in the study. The average milk yield in the previous lactation was $7500 \pm 9501$. Cows were divided into two groups, 15 cows in the experimental and 15 cows in the control group. The experimental group was treated with niacin 14 days prior to the expected calving date and 14 days after parturition. Niacin (Rovimax ${ }^{\mathbb{R}}$ Niacin, F. Hoffmann-La Roche AG, Switzerland) was administered per os with food, $120 \mathrm{~g} / \mathrm{d}$ per cow. The dose of niacin was determined according to a next characteristic: the bioavailability of unprotected niacin is about $10 \%$; in most experimental models 6 or $12 \mathrm{~g} / \mathrm{d}(10 \%$ of $120 \mathrm{~g} / \mathrm{d})$ of protected nicotinic acid was supplemented to cows. Niacin was in the form of nicotinic acid and in a rumen-unprotected form. The control group was not treated with niacin. All the cows were fed and taken care of in a similar fashion, meeting daily NRC standards (2001).

Blood samples were collected by venipuncture from the coccygeal vein before morning feeding and were taken three times, on the week of calving and during the first and second week after parturition. Blood samples for biochemical analysis were collected in sterile $10-\mathrm{ml}$ vacuum tubes with gel separator (BD Vacutainer ${ }^{\circledR}$ SST II Advance, BD Plymouth, UK, they contain no other additives other than the clot activator and gel for serum separation) and appropriately marked. After centrifugation of the blood samples at $4000 \times g$ for 10 min, plasma was obtained. The samples were kept on dry ice and protected from light until laboratory analysis. Samples were analyzed immediately after sampling.

\section{Measurements of metabolic properties}

Blood samples were taken in the week of calving and in the $1^{\text {st }}$ and $2^{\text {nd }}$ week after calving (weeks 0,1 and 2). NEFA and glucose concentrations were determined using colorimeters (Randox, UK and Pointe Scientific, USA) and a semi-automatic biochemistry analyser (Rayto RT/1904cv, China). Insulin was measured with the enzymelinked immunosorbent assay (ELISA) kit manufactured by Cusabio (code: CSB-E11993B, China), and the results were read and interpreted by the ELISA reader (Rayto, China).

\section{Calculation and statistical analyses}

The index of insulin resistance was calculated on the basis of the following insulin resistance indicators: the glucose-to-insulin (G:I) ratio and Revised Quantitative Insulin Sensitivity Check Index (RQUICKI). The formula for the glucose-to-insulin ratio is as follows: $\mathrm{G}: \mathrm{I}=$ glucose $(\mathrm{mg} / \mathrm{dl}) /$ insulin $(\mu \mathrm{U} / \mathrm{ml})$. The RQUICKI is calculated on the basis of the blood plasma concentrations of glucose in $\mathrm{mg} / \mathrm{dl}$, insulin in $\mu \mathrm{U} / \mathrm{ml}$ and free fatty acids in $\mathrm{mmol} / \mathrm{l}$. The formula is as follows: RQUICKI $=1 /[\log ($ glucose $\mathrm{mg} / \mathrm{dl})+\log ($ insulin $\mu \mathrm{U} / \mathrm{ml})+\log (\mathrm{NEFA}$ mmol/l)] (Holtenius and Holtenius 2007). The influence of niacin supplementation and the week of and after calving on the glucose, insulin and NEFA concentrations, as well as the RQUICKI values, were analysed by the ANOVA method. All samples $(n=15$ cow $\times 3$ week $=45)$ from the supplemented and control cows were divided, according to the RQUICKI values, into a more resistant group (RQUICKI < 0.5) and a less resistant group 
(RQUICKI $\geq 0.5$ ). Differences in glucose, insulin and NEFA concentrations between the two groups were determined by $t$-test. Moreover, a linear regression analysis $(\mathrm{Y}=\mathrm{bXi}+\mathrm{a})$ was performed on the basis of all the indicator values obtained in the supplemented and control groups in order to determine differences in the slope of regression lines (differences in the $b$ variables).

\section{Results}

The RQUICKI values obtained were not affected by niacin supplementation and the time of and after calving. The oral supplementation of niacin induced significant treatment effects on the plasma NEFA, glucose and insulin concentrations. The blood NEFA concentrations were lower, whereas the glucose and insulin concentrations were higher in cows supplemented with niacin in all weeks after calving. A time effect was observed on the glucose and insulin concentrations in the control and niacin groups, and on the NEFA concentration in the control group. The glucose and insulin concentrations significantly decreased, whereas the NEFA concentrations increased from weeks 0 to 2 after calving. All the results are presented in Table 1.

Table 1. Influence of niacin supplementation on the metabolic indices and insulin resistance in cows during early lactation.

\begin{tabular}{llccccc}
\hline \multirow{2}{*}{ Indicator } & & \multicolumn{3}{c}{ Week after calving } & \multirow{2}{*}{ Influence of week } & Influence of niacin \\
\cline { 3 - 5 } & & 0 & 1 & 2 & & \\
\hline RQUICKI & Niacin & $0.5 \pm 0.02$ & $0.5 \pm 0.03$ & $0.51 \pm 0.02$ & NS & NS \\
& Control & $0.5 \pm 0.03$ & $0.49 \pm 0.02$ & $0.49 \pm 0.03$ & NS & \\
G:I ratio & Niacin & $9 \pm 1.5$ & $8.4 \pm 1.2$ & $8.1 \pm 1.1$ & NS & NS \\
& Control & $9.8 \pm 1.2$ & $8.6 \pm 1.3$ & $8.7 \pm 1.4$ & NS & \\
Glucose $(\mathrm{mg} / \mathrm{dl})$ ) & Niacin & $55.7 \pm 5.9$ & $49.2 \pm 5.4$ & $45.5 \pm 5.3$ & $<0.05$ & $<0.01$ \\
& Control & $45.6 \pm 4.1$ & $38.1 \pm 5.6$ & $36.2 \pm 5.4$ & $<0.05$ & \\
Insulin $(\mu \mathrm{U} / \mathrm{ml})$ & Niacin & $6.1 \pm 0.65$ & $5.8 \pm 0.7$ & $5.6 \pm 0.45$ & $<0.05$ & $<0.01$ \\
& Control & $4.65 \pm 0.52$ & $4.4 \pm 0.6$ & $4.01 \pm 0.5$ & $<0.05$ & \\
NEFA $(\mathrm{mmol} / \mathrm{l})$ & Niacin & $0.31 \pm 0.12$ & $0.35 \pm 0.15$ & $0.38 \pm 0.13$ & $\mathrm{NS}$ & $<0.01$ \\
& Control & $0.47 \pm 0.13$ & $0.63 \pm 0.13$ & $0.75 \pm 0.14$ & $<0.01$ & \\
\hline
\end{tabular}

RQUICKI- Revised Quantitative Insulin Sensitivity Check Index; G:I ratio - glucose to insulin ratio;NEFA non-esterified fatty acid

Higher glucose, insulin, and NEFA concentrations are a sign of insulin resistance in cows supplemented with niacin. These concentrations were found in cows with a RQUICKI $<0.5$ in comparison with cows with a RQUICKI $\geq 0.5$ (Table 2). There were no significant differences in the metabolic indices in the control group with regard to the RQUICKI values.

The insulin response to glucose was more intense in the group supplemented with niacin (Fig. 1). The antilipolytic effect of insulin was lower in the supplemented than in the control group (Fig. 2). A negative correlation between the NEFA concentrations and G:I index was determined in cows supplemented with niacin, whereas a non-significant correlation was recorded in the control group (Fig. 3). The RQUICKI index was much more regressed with the NEFA, glucose and insulin concentrations in the supplemented cows in comparison with the negative control group (Figs 4-6). Decreased NEFA concentrations in the niacin group resulted in an increased RQUICKI and G:I index, which indicates a higher insulin sensitivity than in the control group. A high response of insulin to glucose, a lower response of NEFAs to insulin and a significantly decreased RQUICKI, with regard to the increased glucose and insulin concentrations, are indicators of the insulin resistance in cows supplemented with niacin. 
Table 2. Influence of RQUICKI values on the metabolic indices in cows during early lactation.

\begin{tabular}{|c|c|c|c|c|c|}
\hline & & \multicolumn{2}{|c|}{ RQUICKI } & \multirow[t]{2}{*}{ Influence of RQUICKI } & \multirow[t]{2}{*}{ Influence of niacin } \\
\hline & & $\geq 0.5(\mathrm{n}=20)^{*}$ & $<0.5(\mathrm{n}=25)$ & & \\
\hline \multirow[t]{2}{*}{ Glucose (mg/dl) } & Niacin & $53.4 \pm 6.2$ & $47.7 \pm 6.1$ & $<0.01$ & $<0.01$ \\
\hline & Control & $41.3 \pm 5.6$ & $38.24 \pm 6.6$ & NS & \\
\hline \multirow[t]{2}{*}{ Insulin $(\mu \mathrm{U} / \mathrm{ml})$} & Niacin & $6.27 \pm 0.62$ & $5.6 \pm 0.61$ & $<0.01$ & $<0.01$ \\
\hline & Control & $4.54 \pm 0.55$ & $4.21 \pm 0.64$ & NS & \\
\hline \multirow[t]{2}{*}{ NEFA (mmol/1) } & Niacin & $0.46 \pm 0.08$ & $0.33 \pm 0.09$ & $<0.01$ & $<0.01$ \\
\hline & Control & $0.67 \pm 0.16$ & $0.58 \pm 0.16$ & NS & \\
\hline \multirow[t]{2}{*}{ G:I ratio } & Niacin & $8.5 \pm 0.8$ & $8.6 \pm 0.9$ & NS & NS \\
\hline & Control & $9.2 \pm 0.9$ & $9.2 \pm 1$ & NS & \\
\hline
\end{tabular}

RQUICKI- Revised Quantitative Insulin Sensitivity Check Index; G:I ratio - glucose to insulin ratio; NEFA - nonesterified fatty acid

*All samples $(\mathrm{n}=15 \mathrm{cow} \times 3$ week $=45)$ from the supplemented and control cows were divided according to the RQUICKI values

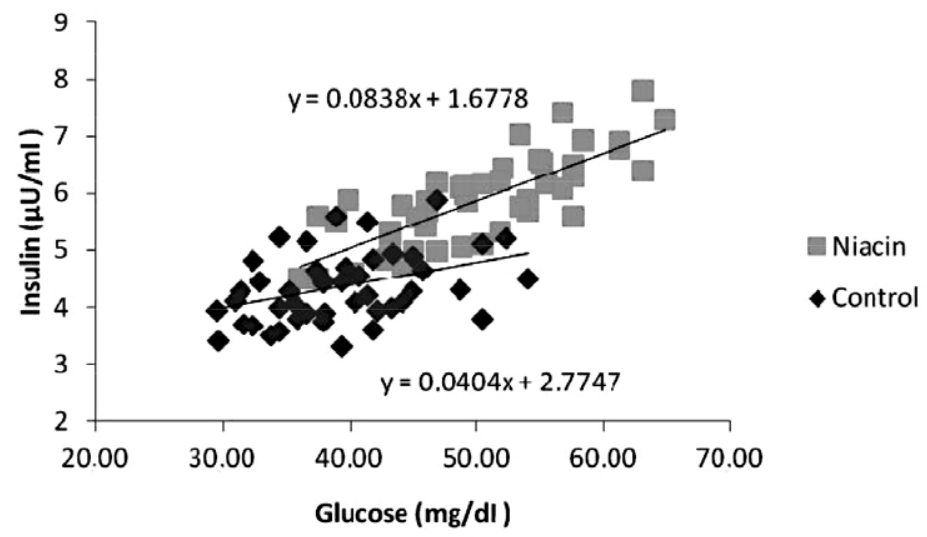

Fig. 1. Relation between glucose and insulin in the niacin-supplemented and control cows

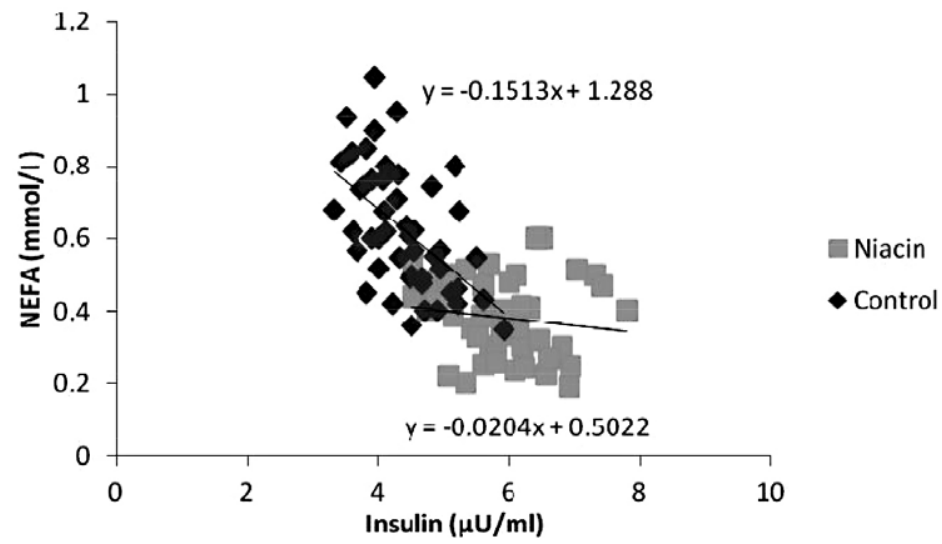

Fig. 2. Relation between insulin and non-esterified fatty acid (NEFA) in the niacin-supplemented and control cows 


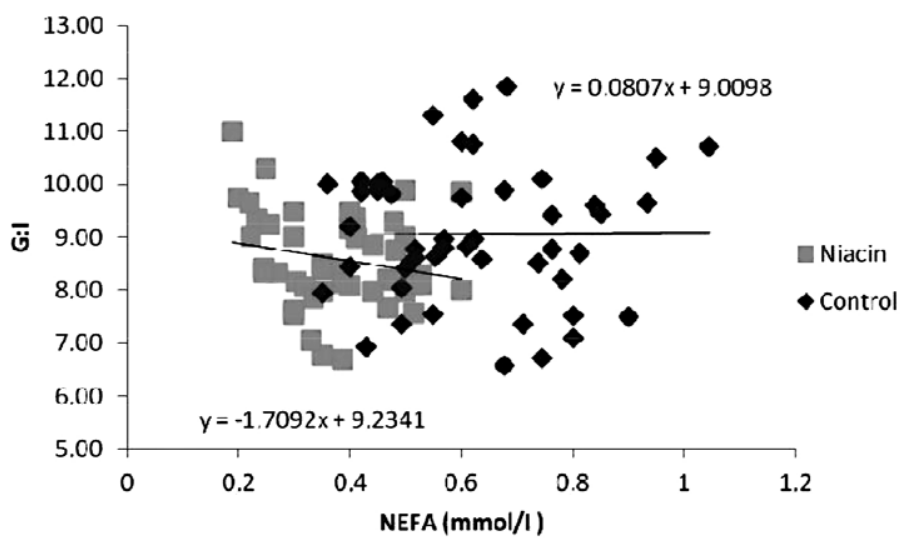

Fig. 3. Relation between non-esterified fatty acid (NEFA) and a glucose to insulin ratio (G:I) in the niacinsupplemented and control cows

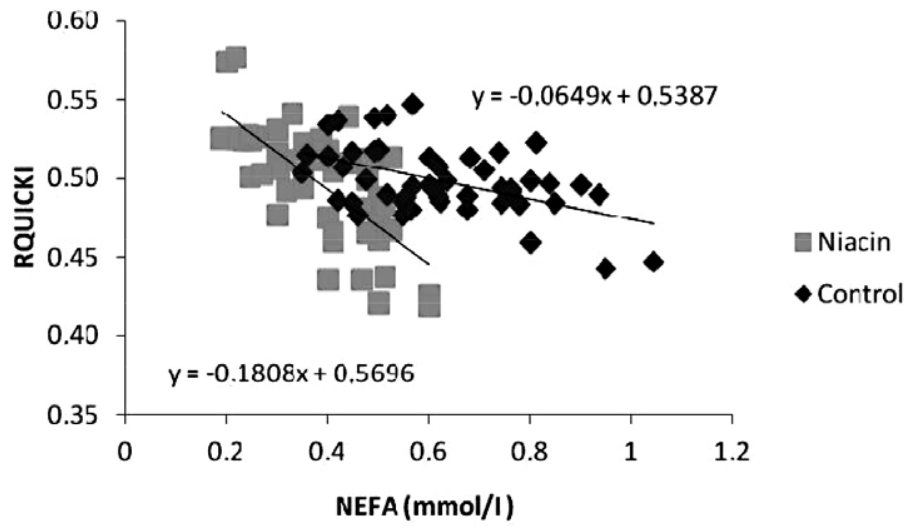

Fig. 4. Relation between Non-Esterified Fatty Acid (NEFA) and Revised Quantitative Insulin Sensitivity Check Index (RQUICKI) values in the niacin supplemented and control cows

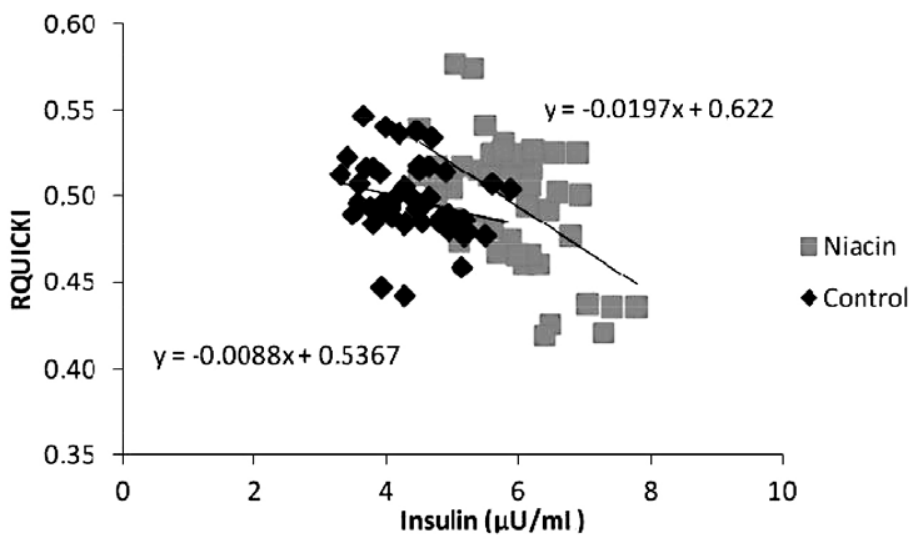

Fig. 5. Relation between insulin and Revised Quantitative Insulin Sensitivity Check Index (RQUICKI) in the niacin-supplemented and control cows 


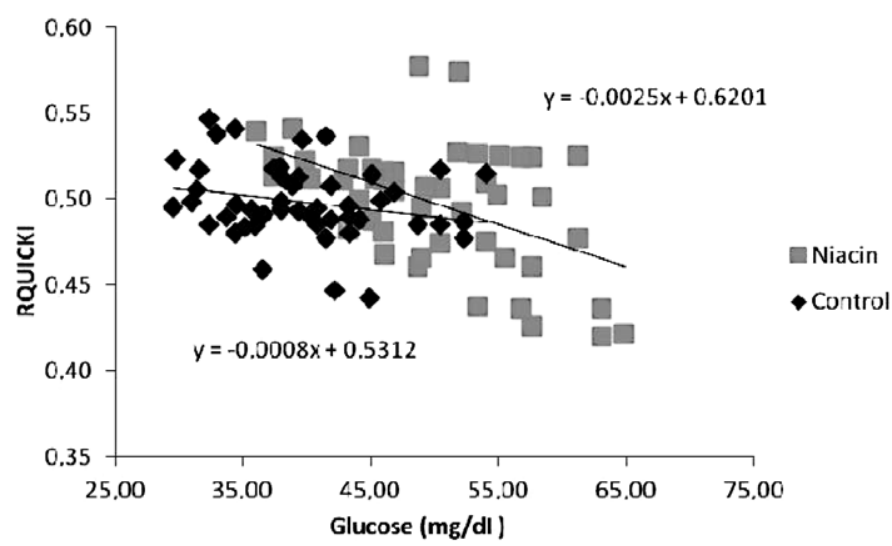

Fig. 6. Relation between glucose and Revised Quantitative Insulin Sensitivity Check Index (RQUICKI) in the niacin-supplemented and control cows

\section{Discussion}

In the review article by Niehoff et al. (2009), the use of niacin which is not rumenprotected was analysed. The authors concluded that NEFA concentrations can be reduced by nicotinic acids under certain conditions, but not by nicotinamide. Cows were supplemented with 6 or $12 \mathrm{~g}$ /day of nicotinic acid and the dose effect on metabolic indices depended on the experimental procedure. High doses of nicotinic acid demonstrate the ability to reduce the NEFA release from adipose tissues (Pires et al. 2007b; Pires and Grummer 2007) with the activation of niacin receptors GPR109A (Gille et al. 2008). Niacin exerts inhibiting effects on the lipolysis in the adipose tissue, leading to a decrease in the plasma NEFA concentrations (Carlson 2005; Yuan et al. 2012). High doses of niacin reduced the NEFA release from the adipose tissue in the ketotic cow (Waterman et al. 1972). In our study, glucose concentrations were significantly higher in cows that received niacin compared to the control group during all the weeks of examination. Other authors (Doreau and Ottou 1996; Di Constanzo 1997; Ghorbani et al. 2008; Karkoodi and Tamizrad 2009) have found similar results, i.e. cows that received niacin indicated elevated plasma glucose concentrations in comparison with the control group. Thornton and Shulz (1980) found a positive correlation between plasma glucose concentrations and doses of the niacin administered. An increase in the blood glucose concentrations after niacin administration may be a result of greater gluconeogenic activity (Di Constanzo 1997), decreased glucose removal (Jaster and Ward 1990) or increased hepatic glucose production (Pescara et al. 2010). Pescara et al. (2010) found that plasma insulin concentrations followed a response pattern similar to plasma glucose concentrations during the nicotinic acid infusion, and that niacin administration is responsible for increased glucose and insulin concentrations.

Insulin resistance develops in many species during gestation and continues during lactation. Insulin resistance is a pathophysiological term which describes a decreased response of insulin to glucose. Moreover, it is a decreased function of $\beta$-cells (insulin responsiveness) and/or an increased resistance of the peripheral tissue to insulin (insulin sensitivity) (Kahn 1978; De Koster and Opsomer 2013). Insulin responsiveness is higher in cows supplemented with niacin, but the response of fat tissue to insulin is lower. Insulin release is higher when insulin sensitivity is lower: lower sensitivity indicates higher resistance (Kahn et al. 2006). In addition, the results of intravenous glucose tolerance tests show a decreased insulin response in cows with ketosis, when there is a significant negative 
energy balance (Đoković et al. 2014), and thus a higher response of insulin to glucose could be a beneficial effect of niacin in early lactation. The glucose-to-insulin ratio is lower in the supplemented cows. A lower G:I index indicates the insulin resistance in humans (Quon 2001). Bossaert et al. (2008) suggest that NEFAs impair the glucose-induced insulin secretion in dairy cows. The RQUICKI index is greatly affected by the NEFA, glucose and insulin concentrations in cows supplemented with niacin. In early lactation cows, the RQUICKI index is significantly affected by the NEFA values (Cincović et al. 2014), thus a decrease in NEFA concentrations increases the insulin sensitivity in cows supplemented with niacin. Increased NEFA concentrations may play a role in reducing the insulin responsiveness in adipose tissue in non-lactating fasting cows (Oikawa and Oetzel 2006). Furthermore, NEFAs may impair the glucose-induced insulin secretion and decreased glucose and insulin clearance after glucose tolerance testing in dairy cows (Bossaert et al. 2008). High NEFA concentrations inhibit the insulin-stimulated use of glucose in skeletal muscles and suppress hepatic glycogenolysis (Hayirli 2006). The direct harmful effects of NEFAs on pancreatic $\beta$ cells were demonstrated on adult rats (Meadler et al. 2001).

In conclusion, the administration of niacin increased glucose and insulin concentrations, and decreased NEFA concentrations. The decreased NEFA concentrations led to a decrease in the insulin resistance in dairy cows (due to an increase in G:I and RQUICKI values), but the increased concentrations of insulin and glucose caused an increase in the insulin resistance in dairy cows (due to lower RQUICKI values and probably less significant antilipolytic effects of insulin). Niacin exerted a dual influence on the insulin resistance in dairy cows during early lactation. The impact of niacin in early lactation requires further research.

\section{Acknowledgement}

This research was supported by the Ministry of Education, Science and Technological Development of Serbia, Project No. TR31062.

\footnotetext{
References

Butler WR 2000: Nutritional interactions with reproductive performance in dairy cattle. Anim Reprod Sci 60-61: 449-457

Bell AW 1995: Regulation of organic nutrient metabolism during transition from late pregnancy to early lactation. J Anim Sci 73: 2804-2819

Bender DA 2003: Niacin. In: Nutritional biochemistry of the vitamins. $2^{\text {nd }} \mathrm{edn}$. Cambridge University Press, Cambridge, pp 200-231

Bossaert P, Leroy JL, De Vliegher S, Opsomer G 2008: Interrelation between glucose-induced insulin response, metabolic indicators, and the time of first ovulation in high-yielding dairy cows. J Dairy Sci 91: 3363-3371

Carloson LA 2005: Nicotinic acid: The broad-spectrum lipid drug. A 50 ${ }^{\text {th }}$ anniversary review. J Intern Med 258: 94-114

Cincović MR, Belič B, Đoković R, Toholj B, Hristovska T, Delić B, Došenovć M 2014: Insulin resistance in cows during dry period and early lactation. Contemporary Agriculture 3: 98-105

De Koster JD, Opsomer G 2013: Insulin resistance in dairy cows. Vet Clin North Am Food Anim Pract 29: 299-322

Di Costanzo A, Spain JN, Spiers D 1997: Supplementation of nicotinic acid for lactating Holstein cows under heat stress conditions. J Dairy Sci 80: 1200-1206

Doreau M, Ottou JF 1996: Influence of niacin supplementation on in vivo digestibility and ruminal digestion in dairy cows. J Dairy Sci 79: 2247-2254

Drackley JK 1999: Biology of dairy cows during the transition period: The final frontier? J Dairy Sci 82: 2259-2273

Dyk PB, Emery RS, Liesman JL, Bucholtz HF, VandeHaar MJ 1995: Prepartum non-esterified fatty acids in plasma are higher in cows developing periparturient health problems. J Dairy Sci 78: 264

Đoković R, Kurčubić V, Ilić Z, Cincović M, Davidov I, Petrović MD, Trifkovic J 2014: Changes in blood values of glucose, insulin and inorganic phosphorus in healthy and ketotic cows during an intravenous glucose tolerance test. Biotechnology in animal husbandry 30: 571-578
} 
Ghorbani B, Vahdani N, Zerehdaran S 2008: Effects of niacin on milk production and blood parameters in early lactation of dairy cows. Pak J Biol S 15: 1582-1587

Grummer RR 1993: Etiology of lipid-related metabolic disorders in periparturient dairy cows. J Dairy Sci 76: 3882-3896

Gille A, Bodor ET, Ahmed K, Offermanns S 2008: Nicotinic acid: Pharmacological effects and mechanisms of action. Ann Rev Pharmacol Toxicol 48: 79-106

Hayirli A 2006: The role of exogenous insulin in the complex of hepatic lipidosis and ketosis associated with insulin resistance phenomenon in postpartum dairy cattle. Vet Res Commun 30: 749-774

Holtenius P, Holtenius K 2007: A model to estimate insulin sensitivity in dairy cows. Acta Vet Scand 49: 29-31

Jaster EH, Ward NE 1990: Supplemental nicotinic acid or nicotinamide for lactating dairy cows. J Dairy Sci 73: 2880-2887

Kahn CR 1978: Insulin resistance, insulin insensitivity, and insulin unresponsiveness: a necessary distinction. Metabolism 27: 1893-1902

Kahn SE, Hull RL, Utzschneider KM 2006: Mechanisms linking obesity to insulin resistance and type 2 diabetes. Nature 444: 840-846

Karkoodi K, Tamizrad K 2009: Effect of niacin supplementation on performance and blood parameters of Holstein cows. S Afr J Anim Sci 39: 349-354

Kenéz A, Locher L, Rehage J, Dänicke S, Huber K 2014: Agonists of the G protein-coupled receptor 109A-mediated pathway promote antilipolysis by reducing serine residue 563 phosphorylation of hormonesensitive lipase in bovine adipose tissue explants. J Dairy Sci 97: 3626-3634

Morey SD, Mamedova LK, Anderson DE, Armendariz CK, Titgemeyer EC, Bradford BJ 2011: Effects of encapsulated niacin on metabolism and production of periparturient dairy cows J Dairy Sci 94: 5090-5104

Maedler K, Spinas GA, Dyntar D, Moritz W, Kaiser N, Donath MY 2001: Distinct effects of saturated and monounsaturated fatty acids on ß-cell turnover and function. Diabetes 50: 69-76

Niehoff ID, Huther L, Lebzien P 2009: Niacin for cattle: A review. Br J Nutr 101: 5-19

NRC 2001: Nutrient Requirements of Dairy Cattle. Seventh revised edition. National Academy Press Washington, D.C., USA

Overton TR 2001: Transition cow program. The good, the bad, and how to keep them from getting ugly. Advances in Dairy Technology 13: 17-25

Oikawa S, Oetzel GR 2006: Decreased insulin response in dairy cows following a four-day fast to induce hepatic lipidosis. J Dairy Sci 89: 2999-3005

Petersen FK, Shulman GI 2006: New insights into the pathogenesis of insulin resistance in humans using magnetic resonance spectroscopy. Obesity 14: 34-40

Pescara JB, Pires AA, Grummer RR 2010: Antilipolytic and lipolytic effects of administering free or ruminally protected nicotinic acid to feed-restricted Holstein cows. J Dairy Sci 93: 5385-5396

Pires JAA, Grummer RR 2007: The use of nicotinic acid to induce sustained low plasma nonesterified fatty acids in feed-restricted Holstein cows. J Dairy Sci 90: 3725-3732

Pires JAA, Souza AH, Grummer RR 2007: Induction of hyperlipidemia by intravenous infusion of tallow emulsion causes insulin resistance in Holstein cows. J Dairy Sci 90: 2735-2744

Pires JAA, Pescara JB, Grummer RR 2007b: Reduction of plasma NEFA concentration by nicotinic acid enhances the response to insulin in feed-restricted Holstein cows. J Dairy Sci 90: 4635-4642

Pullen DL, Palmquist DL, Emery RS 1989: Effect on days of lactation and methionine hydroxy analog on incorporation of plasma fatty acids into plasma triglycerides. J Dairy Sci 72: 49-58

Quon MJ 2001: Limitations of the Fasting Glucose to Insulin Ratio as an Index of Insulin Sensitivity. J Clin Endocrinol Metab 86: 4615-4617

Thornton JH, Schultz LH 1980: Effects of administration of nicotinic acid on glucose, insulin, and glucose tolerance in ruminants. J Dairy Sci 63: 262-268

Waterman R, Schwalm J, Shultz W 1972: Nicotinic acid treatment of bovine ketosis I. Effects on circulatory metabolites and interrelationships. J Dairy Sci 55: 1447-1453

Wise A, Foord SM, Fraser NJ, Barnes AA, Elshourbagy N, Eilert M, Ignar DM, Murdock PR, Steplewski K, Green A, Brown AJ, Dowell SJ, Szekeres PG, Hassall DG, Marshall FH, Wilson S, Pike NB 2003: Molecular identification of high and low affinity receptors for nicotinic acid. J Biol Chem 278: 9869-9874

Yuan K, Shaver RD, Bertics SJ, Espineira M, Grummer RR 2012: Effect of rumen-protected niacin on lipid metabolism, oxidative stress, and performance of transition dairy cows. J Dairy Sci 95: 2673-2679 